\title{
Записки из подполья Ф. М. Достоевского В свете литературной традиции: Семиотическая постановка вопроса
}

\begin{abstract}
Katalin Kroó ${ }^{1}$
Абстракт. В настоящей статье повесть Ф. М. Достоевского Записки из подполья рассматривается через концептуализацию литературной традиции в семиотическом контексте, в трех взаимосвязанных аспектах: (1) дискурсивные формы отрицания и его смысловые перспективы (апофатизм); (2) семантизация идеи полноты и (3) ориентированность художественного текста на осмысление семиотической природы изображаемого мира и изображающего (мета)поэтического языка. Если апофатизм в семиотическом плане проблематизирует парадоксальность попытки уловить невыражаемое в интенсивных формах языковой динамики, и познавать перспективы существования личности в описании форм несуществования или амбивалентного / непродуктивного существования, то придавая семиотическую установку изложению характерологии, с ее личностным центром, стремлением к завоеванию опыта полного существования / полноты, в повести Достоевского происходит богатая семантизация семиотического явления беспризнаковости / лишения признаковости в определении познаваемого объекта. В статье прослеживается семантическое моделирование полноты и ее дискредитация в направлениях (а) причинно-следственной мотивации; (б) временной сегментации; (в) детализации в форме исчерпывающего деления объекта описания. Семиотическая динамика в Записках из подполья связана с проблематизацией маркированных противоречий (как в плане характерологии, так и идей - тезисов и антитезисов) и с разработкой - в качестве форм их совместного сохранения - семантического образования инклюзивности. Оно восходит к монодуалистической антиномии, имеющей глубокие корни в религиозно-философской традиции русской культуры. В итоге текстовая динамика произведения Достоевского в статье интерпретируется в рамках модели трансформации: одно то же, что другое (беспризнаковое унифицирование объектов познания) $\rightarrow$ или-или (взаимоисключительность в выборе маркированных индивидуализированных атрибутов объектов познания) $\rightarrow$ u то, и другое (соединение противопоставленностей, единство противоречий). В такой трансформационной модели заложено
\end{abstract}

1 Department of Russian Language and Literature, Eötvös Loránd University, Múzeum krt. 4/D, 1088 Budapest, Hungary; e-mail: katalinkroo@gmail.com. 
толкование семиотической креативности, в свете которой Достоевский определяет понятие культурной традиции. Ее динамику характеризует процессуальность и открытость.

Keywords: Dostoevsky; Notes from the Underground; literary tradition; apophatism; individualization through trait attribution; inclusiveness; monodualistic antinomy; model of semiotic creation

Исследовательская задача, подход к повести Достоевского Записки из подполья в контексте литературной традиции, толкуемой с семиотической перспективы, прежде всего требует выяснения понятия традиции. Оно складывается из нескольких компонентов. Опираясь на термин Ю. Лотмана “культурно-литературный континуум” (Lotman 1988: 330), традицию считаем процессуальным континуитетом в литературной культуре, в рамках которого художественные произведения соотносятся посредством маркированных черт, отождествляемых в области поэтики. Эти свойства создают литературную парадигму - в том смысле, как парадигматичность понимает Вольф Шмид (Schmid 2013); в результате осознается типологическая связность данных текстов - в смысле, как это понимает Виктор Жирмунский (Zhirmunskij 1960). В этом толковании литературная традиция как историко-литературное явление близка к понятию text-coherence, text-connectedness (см., напр., Conte-Petöfi-Sözer 1989), неся информацию о том, как феномен связности текстов по определенным поэтическим критериям проявляется в диахроническом процессе.

Перечислим взаимосвязанные компоненты, которые мы считаем общими элементами той диахронической парадигматичности, в рамках которой в настоящей работе осмысляется традиция. Они составляют комплексный контекст для нашего подхода к Запискам из подполья (далее ЗИП).

Bo-nервых, мышление и речь/дискурс определяется в произведении через модель отрицания, принадлежащая своеобразному литературному персонажу, который получает типическую характеристику (включая и самохарактеристику) именно через отрицание. Такой герой в критической литературе причисляется к условной категории “лишних" или генетически родственных им персонажей и фигур, в изображении которых на передний план выводится проблема и тематизация существования в острой дилемме быmь vs. не быmь (отчасти это и отражается в тематике “нигилизма”). Такая семантизация воплощается в разных культурных универсалиях, как, например, в мотивной дихотомии всё vs. ничего; 
Bo-вторых, в плане доминанты семантизации выделяется смысловое определение идеи полноты;

B-mpembux, тексту повести свойственна поэтическая установка на осмысление семиотической природы миро- и текстопонимания в разных планах, от уровня действия до метатекста.

В таких рамках нашего подхода проводится семиотическая постановка указанных аспектов литературного контекста ЗИП, толкуемого в качестве традиции, и также определяются семиотические стратегии текста, которыми создается своеобразный поэтический универсум повести Достоевского.

\section{1. Модель отрицания}

Обратимся к первому абзацу ЗИП, который можно определить как вариант апофатического рассказа. Он содержит богато семантизированный дискурс, полный смысловых напряжений:

Я человек больной... Я злой человек. Непривлекательный я человек. Я думаю, что у меня болит печень. Впрочем, я ни шиша не смыслю в моей болезни и не знаю наверно, что у меня болит. Я не лечусь и никогда не лечился, хотя медицину и докторов уважаю. К тому же я еще и суеверен до крайности; ну, хоть настолько, чтоб уважать медицину. (Я достаточно образован, чтоб не быть суеверным, но я суеверен.) Нет-с, я не хочу лечиться со злости. Вот вы этого, наверно, не изволите понимать. Ну-с, а я понимаю. Я, разумеется, не сумею вам объяснить, кому именно я насолю в этом случае моей злостью; я отлично хорошо знаю, что и докторам я никак не смогу “нагадить” тем, что у них не лечусь; я лучше всякого знаю, что всем этим я единственно только себе поврежу и никому больше. Но все-таки, если я не лечусь, так это со злости. Печенка болит, так вот пускай же ее еще крепче болит! (Dostoevskij 1973a: $99^{2}$ )

Первое впечатление, полученное читателем от абзаца, сводится к тому, что текст закрывается “на себя” (Lahusen 1987: 5), ведь начало и конец содержат мотивные варианты больной/болит - злой/злость. ${ }^{3}$ Сегмент как бы служит доказательством того, что аналитический ум, логическая аргументация, доведенная до крайности ясным разумом, никуда не ведут, они

2 В статье все цитаты из ЗИП даются по указанному изданию. Далее отмечаются только номера страниц.

3 Анализ абзаца см.: Martinsen 2006: 159-160. 
безрезультативны. О таком свойстве будет подробно говорить подпольный человек и приводить в обилии примеры в последующих своих записках, объясняя таким образом свой значительный недостаток, неспособность к адекватному поступку. Из-за такого недостатка и его характер и его жизнь характеризуются устойчивостью, статичностью.

Тем не менее, приведенный отрывок выказывает высшую степень динамичности в плане изображающей системы, а под этой динамичностью обнаруживается последовательное изложение важных смысловых трансформаций, которые указывают на то, что сам язык превращается в агента. Текст, как дискурсивная продукция, своей интенсивной перформативностью мощно действует и совершает разные переоценки в качестве активных преображений.

В соотношении начала и конца абзаца налицо контраст, созданный двумя образами. Первое предложение представляет собой нейтральное утверждение, требующее объяснения, дополнения, продолжения, которые и приводятся. Получается тройное определение утверждения (“Я человек больной... Я злой человек. Непривлекательный я человек.”) Конец воплощает совсем другую модальность: субъект позволяет боли действовать и как бы формулирует псевдо-пожелание (“Печенка болит, так вот пускай же ее еще крепче болит!”). Странность такого пожелания объясняется злостью подпольного человека (“так это со злости”). Сочетанием мотивов боли и злости еще нагляднее связываются начало и конец, ведь в начале мотивные варианты приводятся в форме “человек больной” и “злой человек”. В конце прилагательные превращаются, с одной стороны, в активный глагол, a, с другой стороны, мотив злого человека, носителя отмеченного качества, преображается в злость как продукт злого. Такая резкая трансформация, однако, является итогом дискурсивного развития абзаца в целом (см. ход трансформаций, начавшийся раньше: “Я человек больной... Я злой [...] у меня болит [...] у меня болит [...] со злости [...] моей злостью [...] со злости [...]. Печенка болит, так вот пускай же ее еще крепче болит!"4). Трансформационный ряд подчеркивает активность злого подпольного человека, создающего собственный характер по типу агентивности, которой он обращается к себе. Он адресует себе злость и боль. И адресует очень интенсивно. По ходу своего объяснения “говорящий” субъект постепенно теряет свою способность к нейтральному сообщению, и модальность его речи становится все более и более страстной.

4 Здесь и далее выделения курсивом в цитатах принадлежат автору настоящей статьи - К. К. 
Таким образом, вырисовывается наглядная оппозиция, которая может улавливаться лишь по ходу текстуальной процессуальности целостного абзаца, а затем последующих частей произведения. Характеристика субъекта дискурса противоречит тому, на что он жалуется немного позже, говоря, что он никем не мог стать, и что он не способен действовать, так как его мучит усиленное сознание. Указанный дискурс, со своей синтаксической построенностью, приемами нагромождения самых разных форм потверждающих и варьирующих повторов и градаций, 5 продвигается вперед по линии интенсификации.

Приведем несколько примеров. ${ }^{6}$ В контексте настоящего микроанализа следует подчеркнуть, что в итоге, при страстном стремлении к негативному самоопределению, перформативность данной дискурсивной единицы и реализованные в ней семантические трансформации в направлении утверждения и подтверждения субъекта путем его превращения в агента языкового действия, акцентируют саму языковую продукцию. Мотивы злость и злоба затем в ЗИП будут связаны с мотивами языка и разных типов речи, в том числе и художественной (через мотивы дразнить себя языком [167] и дразнить фантазией - ср.: “злобно поддразнивая и раздражая себя собственной фантазией” [104]). Уже в самом начале повести перформативность текста передает больше информации о личности и в более полной форме, чем непосредственная тематизация отрицательной характерологии, хотя такая тематизация действует очень сильно. ${ }^{7}$ Языковое действие противоречит важным аспектам негативности, о которых рассказывает подпольный человек в продолжении своих записок. Приведенный отрывок не стирает противоречия, которых он так жаждет, но поднимает их в другую онтологическую сферу, ставя их в зону конфликта между изображаемым (семантикой означаемого) и изображающим языком (означающим). Перед нами своеобразный тип апофатического дискурса. Устанавливаются рамки для тематизации отрицания, которое в остальных частях ЗИП в более развернутой форме будет связано с осмыслением отсутствия “живой жизни”, вообще с разными аспектами состояния не быть или лишения адекватной формы и содержания бытия. В

5 См., напр., “я ни шиша не смыслю [...] и не знаю [...] Я не лечусь и никогда не лечился $[\ldots]$ я не хочу лечиться"; “я отлично хорошо знаю” $\rightarrow$ “я лучше всякого знаю, что”; “я ни [...] Я не" $\rightarrow$ “К тому же я еще [...]”.

6 Одновременно напомним, что общей проблеме апофатизма и стилистики ЗИП были посвящены такие выдающиеся работы, как, например, статья Томаса Лахузена (Lahusen 1987) или работа Натальи Живолуповой (Zhivolupova 2018).

7 См.: “Непривлекательный я [...] я ни шиша не смыслю [...] не знаю [...] Я не лечусь и никогда не лечился [...] я не хочу лечиться со злости. [...] не сумею вам объяснить [...] не лечусь [...]". 
то же время, при отрицании, в данных же рамках, порождается утверждение личности не как положительность характера, не в моральной оценке, а просто как констатация личностного существования, его силы и того факта, что эта сила проявляется в дискурсивном акте творения текста как процесса максимализации (нагромождения, градации, интенсификации, семантического обогащения, расширения) - одним словом, как процесса достижения переживаемой в тексте полноть.

Для сравнения приведем подобный пример из Героя нашего времени, хотя там речь идет о дискурсивной презентации не Печорина, а Веры, но в рамках персонального повествования Журнала Печорина. Сила личности героя выражается языковой насыщенностью, имеющей перформативную творящую силу в повторах отрицательного в целях выражения положительного:

Моя душа истощила на тебя все свои сокровища, свои слезы и надежды [...] никто не умеет так постоянно хотеть быть любимым; ни в ком зло не бывает так привлекательно, ничей взор не обещает столько блаженства, никто не умеет лучше пользоваться своими преимуществами, - и никто не может быть так истинно несчастлив, как ты, потому что никто столько не старается уверить себя в противном. (Lermontov 2000: 350)

Возьмем другие строки из романа Бесы Достоевского, где по письму Ставрогина к Даше можно проследить вариант подобной дискурсивной стратегии:

В России я ничем не связан, - в ней мне все так же чужое, как и везде. Правда, я в ней более, чем в другом месте, не любил жить; но даже и в ней ничего не мог возненавидеть! (Dostoevskij 1974: 513)

Усиление отрицания происходит в процессе интенсификации, к концу которого формируется смысл максимализированности любви к жизни человека, говорящего о себе, что возненавидеть жизнь (достигнуть высокой степени ее отказа) даже в верхней точке отрицания он не может. Корни такой композиции и языковой активации дискурса, как говорилось, восходят к апофатической традиции. В плане языка апофатизм характеризуется “бурной языковой активностью”, часто соединяемой с “риторикой амплификации”, установкой на “максималистские литературные и когнитивные амбиции" (ср. Lunde 2001: 266 ${ }^{8}$ ).

8 Наш перевод - К. К; ср.: “[...] an apophatic approach may lead, paradoxically, to feverish linguistic activity. More specifically, the 'rhetoric of apophaticism' is often turned into, or 
Возвращаясь к исходному плану поставить толкование поэтики ЗИП в контекст литературной традиции по трем линиям исследования - см.: (1) модель отрицания, (2) семантизация полноты и (3) нюансированная проблематизация семиотичности мышления и дискурса, - можно заключить, что в принципе само явление апофатической традиции наррации включает в себя все три указанных аспекта: (1) действует негативное выражение позитивного (упрощенно говоря: утверждение в форме отрицания); (2) в этом же процессе проявляется максимализация и полная активация резервов языкового выражения, которое призвано восполнить дефицит в парадоксальной когнитивной ситуации - парадоксальность в том, что такой ситуации свойственны трудности эпистемологической доступности, понимания невыражаемого, которому все же нужно придать формулировку как раз в целях его толкования, к тому же нужно найти полное выражение для понимания полноты явления (хорошо известно, что в негативной теологии речь идет о приближении к осмыслению сути Бога и божественной природы, трансцендентального, а полным выражением такого процесса может стать даже молчание). Из всего этого вытекает концептуализация парадоксальности полноты; но из двух названных аспектов ясно и то - и это уже третий момент, - что (3) проблема познания познаваемого объекта сводится к языковому вопросу в его семиотическом аспекте. В изложении такой проблематики получает акцент соотношение выражения (отображения путем знаковой артикуляции) и содержания (значения) того, для чего нельзя найти непосредственную форму выражения.

\section{2. Поэтическая семантизация идеи полноты}

\section{1. Формы семантизации в свете русской литературной традиции}

Учитывая сказанное, все же нельзя думать, что апофатическая традиция сама по себе может дать исчерпывающее объяснение сочетаемости названных трех аспектов парадигматичности, порождающей литературную традицию, к которой мы стараемся отнести ЗИП Достоевского. В русской литературе XIX века обращают на себя внимание многочисленные разветвления моделирования стремления к переживанию, пониманию и обозначению опыта полноты и иелостности:

combined with, a 'rhetoric of amplification"; ср. тоже: "maximalistic" "literary and cognitive ambitions" (Lunde 2001: 266). Ср. Ханзен-Леве о “суггестивности дискурса”: Hansen-Löve 1996: 231. 
(1) Разрабатывается поэтическая модель хронотопной тотальности в качестве примера можно привести стихотворение Лермонтова Выхожу один я на дорогу.... Там лирический герой завоевывает для себя все пространства и все временные измерения. Условно это можно назвать хронотопной идеей omnipraesentia - быть везде, углубляясь во все времена. В определенном варианте такая черта интенсивности уметь присутствовать в пространстве и во времени появляется и в таких романах, как Рудин Тургенева или Идиот Достоевского.

(2) Изображаются стремления персонажей овладеть всеми видами переживаний. Это модель экстенсивной тотальности (известной, помимо прочего, по типу переживаний байроновского Дон Жуана). Вернемся хотя бы к печоринскому опыту - все попробовать, накапливать всевозможные виды опыта (ср. Савинков; Фаустов 2014).

(3а) Такому освоению опыта полноты и его пониманию противопоставлено свойство интенсивной тотальности. Возьмем, например, Мышкина с его идеалом “каждую минуту в целый век обратил” (Dostoevskij 1973b: 52); или описание его эпилепсии, той секунды, “самого последнего сознательного момента перед припадком, когда ему случалось [...] сознательно сказать себе: «Да, за этот момент можно отдать всю жизнь!»” (ibid., 188). Речь идет о завоевании полноты переживания во всей ее интенсивности, когда “минута ощущения”, оказывающаяся “в высшей степени гармонией, красотой, дает неслыханное и негаданное дотоле чувство полноты, меры, примирения и восторженного молитвенного слития с самым высшим синтезом жизни" (ibid.; см. полноту как синтез).

(36) Особую разновидность представляют собой формы семантизации единичной минуты, мига, изображение разных попыток приобрести все блага жизни слишком быстро - см. модель неудачи достигнуть всего одним махом (Пиковая дама, Игрок, Преступление и наказание) или преждевременно (Дума Лермонтова).

(4) Создается комплексная система целостно переживаемой временной системы бытия в поэзии - см. элегчческую тотальность времени со сложными формами соотношения настоящего, прошлого и будущего, через ретроспективную, проспективную и ретро-проспективную перспективы.

(5) Получают большое значение формы тематизации, связанные с мифологемами - см., напр., золотой век в качестве непочатой 
тотальности, еще неутраченной иелостности, полноть; мифологему продажи души (договор с дьяволом), ср.: отдать всю душу за всю жизнь, за все блага (Импровизатор Одоевского). Здесь следует упомянуть и универсалии русской культуры, как, например, мотивное образование всё-ничего (достаточно привести главный диалог между Одинцовой и Базаровым о любви и о возможности для человека целиком, полностью отдаться другому, девиз всё или ничего в любви).

(6) Получает оживленную семантизацию соотношение части и целого, индивида и поколения, частного и общего, субъекта и целостного миропостроения - помимо прочего и соприкасаясь с этим вопросом может толковаться проблематизация фрагментарности.

Все это говорит о том, что семантизация стремления к достижению полноты, которое в первом абзаце ЗИП можно толковать в контексте апофатической художественной традиции, имеет гораздо более широкий и богатый культурно-литературный фон.

\section{2. Семантизация максимализации и формы ее дискредитации}

В ЗИП Достоевского главным признаком мотива полноты в качестве варианта можно считать тематизацию пропориии и меры. Хорошо известно, что в автохарактеристику подпольного человека входит критика, что он “усиленно сознающая мышь [...] вследствие усиленного сознания” (104), а “слишком сознавать - это болезнь, настоящая, полная болезнь" $\left(101^{9}\right)$. Такой атрибут чрезмерности в перспективе литературной традиции соответствует излишнему и лишности, приводящим к осознанию, например, Чулкатуриным, напрасности существования в Дневнике лишнего человека Тургенева.

Лищний, лишний... Отличное это придумал я слово. [...] Лишний-именно. К другим людям это слово не применяется... Люди бывают злые, добрые, умные, глупые, приятные и неприятные; но лишние... нет. [...] бесполезность - не главное их качество, не отличительный их признак, и вам, когда вы говорите о них, слово “лищний” не первое приходит на язык. А я... про меня ничего

9 См. продолжение: “Для человеческого обихода слишком было бы достаточно обыкновенного человеческого сознания, то есть в половину, в четверть меньше той порции, которая достается на долю развитого человека нашего несчастного девятнадцатого столетия" (ibid.) 
другого и сказать нельзя: лишний-да и только. Сверхштатный человек вот и все. [...] Я был мнителен, застенчив, раздражителен, как все больные; притом, вероятно по причине излишнего самолюбия [...] между моими чувствами и мыслями - и выражением этих чувств и мыслей находилось какое-то бессмысленное, непонятное и непреоборимое препятствие; (Turgenev 1980: 173)

В ЗИП объяснение того, как излишнее сознание не может привести к всеохватывающему переживанию “живой жизни”, получает смысловые уточнения через семантическую модель дискредитации достижения иелостности с установкой на максимализацию. Перечислим несколько элементов модели дискредитации в ЗИП:

(1) Максимализация причинно-следственных мотиваций

Подпольный человек в поиске обоснования своего поступка осознает, что у него “всякая первоначальная причина тотчас же тащит за собою другую, еще первоначальнее, и так далее в бесконечность” (108). Дискредитация приводится, отчасти, в перспективе диссонанса между бесконечным интеллектуальным действием и неумением достичь достаточно удовлетворяющего знания о мире и о себе; не хватает стабилизации “первоначальных"/первичных причин.

(2) Бесконечность во временном аспекте

В чисто временном аспекте бесконечность выражается в инертно повторяющихся у подпольного антигероя механизмах мышления и действия - точнее: их отсутствия; ср. из Бесов мысль “плевать будут тысячу лет” (Dostoevskij 1974: 187). Такой феномен воплощен и в цикличности, когда все вновь и вновь начинается и разыгрывается одинаково. В одном варианте сюда относится все, что не имеет конца - другая сторона того же явления, на которую жалуется подпольный человек: он всю жизнь “ничего не мог ни начать, ни окончить” (109). Модель дискредитации сообщает об аномалиях в линеарном времени, а это приводит к недостаткам в возможности развития личности, в поисках которой подпольный человек прибегает к повышенной форме авторефлексивности. В конечном счете в этом прочтении подвергается крушению динамика развертывания личности.

(3) Бесконечность/вековечность в то же время толкуется в своей связи с праксисом исчерпьвающего деления мира/объекта размышления, в роде освоения полноты в русле подробной до максимума детализации, без оптимальной селекции в целях понимания полной сути познаваемого 
объекта. Это касается, например, припоминания подпольным человеком своей обиды, приводящей к вековечной злости, которая возникает потому, что он “Сорок лет сряду будет припоминать до последних, самых постыдных подробностей свою обиду [...] каждый раз прибавлять от себя подробности поддразнивая [...] собственной фантазией [...] всё припомнит, всё переберет, навыдумает на себя небывальщины [...]” (104). Приведение как можно максимального количества объема анализируемого объекта (всех его действительных, а потом еще и несуществующих фиктивных элементов как продукта фантазии) имеет двойной характер: аналитическим умом деконструируется предмет толкования до последнего атома, в то время как субъект мышления своей фантазией доводит детализацию до максимума небывальщины.

Во всех трех дискредитированных формах максимализации бесконечность служит антитезисом ограниченности, в символическом плане представляемой Стеной. Ограниченность критикуется и через непосредственных людей, "l'homme de la nature et la vérité", которые готовы принимать окончательность аргументов, формул и табличек - т.е. законов природы, одним словом, Стены.

Такое противопоставление ограниченности и бесконечности умеривается не только путем дискредитации указанных трех форм дурной бесконечности, но и путем концептуализации “живой жизни”, которая включает в себя идеал “всей [...] способности жить”, когда “натура человеческая действует вся целиком, всем, что в ней есть, сознательно и бессознательно” (115). Идеал жить действующей “иеликом” человеческой натурой включает в себя как непосредственность, так и аналитический ум, и в повести возникает важное семантическое образование $и$ одно, и другое, не позволяющее исключиться ни одному члену противоречия.

Таким образом создается еще один - четвертый - аспект семантизации полноты и целостности, который условно можно назвать инклюзивностью. Она любопытна тем, что не получает никакой формы семантической дискредитации.

\section{3. Полнота в смысле инклюзивности}

Семантическая фигура инклюзивности в поэтике ЗИП сообщает, что мир полон, если он включает в себя все противоположные элементы. “Живая жизнь” и ее “правда” (ср. 112, 122, 145) как объект познания должны 
содержать в себе все черты, опосредованные интеллектуально для познающего субъекта как тезисы и антитезы; целостность познания предполагает толкование обоих оппозиционных полюсов, но таким образом, чтобы они были осмыслены как взаимосвязанные компоненты целостности, в которой они всё же обладают своими индивидуальными свойствами. ${ }^{10}$

Идея инклюзивности как возможного творения полноты получает нюансированное определение и смысловое развитие в ЗИП в изображении процесса, по ходу которого изначальное противопоставление $я \boldsymbol{v}$. oнu развертывается в сюжете. В этом процессе представлены разные этапы семантизации возможности включиться в мир, т. е. стать частью того интегрального экзистенциального пространства, в котором существуют и подпольный человек как индивидуализированное “я”, и “они” со своими четко определенными антагонистическими признаками.

В данных рамках, не вдаваясь в подробности, отмечу лишь схематично ход развертывания сюжета: “я” vs. “они” $\rightarrow$ попытка включиться в группу “они”, чтобы достичь состояния “мы” (приключения с офицером, со школьниками: неудачные попытки) $\rightarrow$ возможность сотворить состояние “мы с Тобой” (Лиза) $\rightarrow$ мы и вы (я + читатели). В этом русле вопрос инклюзивности сводится к возможности включения в мир и в сферу познания противопоставленных друг другу индивидов - это проблема их совместимости. В плане понятийного мышления - это проблема интеграции тезисов и антитез.

10 Ср. в этом контексте толкование бахтинского понимания разницы между “правдой” и “истиной” в работе: Poole 2001: 163. Правда не может быть определена по принципу универсализации и действия возможного механического повтора. Она творится участником в событии, в котором этот участник в роли единичного субъекта как носителя опыта сам проходит процесс становления личности. Как видно, проблематизация соотношения своеобразно формирующегося, мобильного индивидуального признака и повторяемой устойчивой черты того же явления связана с формированием правды, которую Кэрил Эмерсон осмысляет с перспективы полноты и обилия (Emerson 2001: 189). То, что мир никогда не познаваем со всеми его элементами и аспектами, по сути дела обеспечивает ту полноту, которая аннулирует возможность фиксации устойчивых повторов (т.е. противодействует познавательной застылости - все это в русле апофатизма). В исследовательском контексте настоящей статьи особое значение имеет указанное осмысление понятия правды в свете сочетания идеи индивидуального определения (в противоположность общей/ универсальной миметической повторяемости - речь идет о связи устойчивого повтора и творческого момента в акте познания) с проблемой полноты. 


\section{3. Семиотический код семантического инварианта полноты: признаковость vs. беспризнаковость}

Инвариантный смысл, вокруг которого вращаются все приведенные свойства семантизации полноты, в том числе и вополощенной в инклюзивности, как в сюжете ( $q$ vs. oнu), так и на уровне понятийного мышления (тезисы и антитезы), касается проблематики индивидуализированности (признакового отделения, обособления, дифференциации) и совместимости (сочетаемости) оппозиционных признаков многосоставного, комплексного объекта познания как целостности. Данная проблематика осмысляется с перспективы семиозиса, интерпретируемого с точки зрения означающего и означаемого. Этим мы и пришли к третьему пункту предварительного плана изучения ЗИП Достоевского в свете традиции, под которым проявляется толкование подчеркнутой установки на семиотическую природу моделированных в тексте само- и миропонимания. Беспризнаковость vs. индивидуализированность через специфический признак касается определимости и толкуемости объекта познания в рамках его знаковой отмеченности индивидуальным свойством. Вопрос далее в том, как беспризнаковость становится семантическим инвариантом в указанных четырех аспектах дискредитации модели полноты.

Возьмем сначала явление максимализации причинно-следственных мотиваций. Весьма наглядно, как страстно подпольный человек ищет индивидуализированных первоначальных причин. Он все же не способен найти их, так как все причины наделены тем же свойством: в определенное время они кажутся первоначальными, а затем выясняется, что все они лишаются данного признака. В этом их одинаковость. Результат: эмоции и мысли не могут стать индивидуализированным мотивировочным объяснением поступка. Они сводятся к общему знаменательному “закона сознания"/ природы. Нейтрализация индивидуального признака выражается в специфическом семантическом образовании одно то же, что другое, при котором все сводится к одному и томуже свойству неопределимости в качестве первопричины как индивидуализированного содержания. Или, рассматривая с другого конца, все одинаково может стать новой первичной причиной, еще “первичней”. Речь идет о действии сознания, которое нивелирует индивидуальные признаки в элементах познавательного процесса и, следовательно, не способно обеспечить полный семиозис для познания мира. Получается, что “обида становится не обидой, а фатумом”, т. е. она лишается своеобразного свойства, которое позволило бы отождествить ее именно как обиду (когда обида тождественна самой себе, а не всем 
другим возможным элементам в качестве причины). Здесь же она сводится к чему-то общему с признаком всеохватывающего фатума, “чем-то, вроде зубной боли”, а она ведь определяется как закон природы. В утверждении, “я [...] без вины виноват" (103) проявляется та же логика. Виноват тот, у кого есть вина (как индивидуальный признак виноватости), а если он без вины виноват, то лишился именно личного атрибута отождествимости как настоящего виноватого, и все же считается виноватым. В процессе как бы спецификации данной черты опять унифицируются значения: о великодушии, например, утверждается, что не может вести героя ни к тому, чтобы простить, ни к тому, чтобы забыть, ни отомстить, но даже то все равно (т. е. одно то же, что другое), хочет ли он быть великодушным или невеликодушным, и т. д. и т. п. (ср. 103). Из сказанного вытекает, что мотив несуществования, который в данном контексте появляется как, например, исчезновение злобы, или интеллектуальное уничтожение очередной первичной причины, или воплощается в мотиве “мыльного пузыря” (108), когда “предмет улетучивается, резоны испаряются, виновник не отыскивается, обида становится не обидой, а фатумом..." (108), - этот мотив формируется трехплановым отрицанием: налицо отрицание в плане познаваемого объекта (ср. денотат или референт - “предмет улетучивается”), в плане познающего акта обозначения (“резоны испаряются”), а также в плане отношения означающего и означаемого, знака и его содержания, где это последнее сводится к лишению индивидуального признака. С семиотической перспективы это приводит к омертвению креативного семиозиса.

Все это связано и со вторым аспектом дискредитирующей семантизации (бесконечность в чисто временном аспекте), так как при трехплановым моделировании познавательного акта на передний план выходит субъект познания, который лишен способности к индивидуализации обозначения, следовательно, к творению индивидуального процесса семиозиса. Его этапы оказываются однородными, подобно тому, как предмет познания и сам акт обозначения проявляют аналогию в смысле беспризнаковости. Возникает сильное семантическое образование одно то же, что другое. Остается “болтовня" (109), которая эквивалентна “умышленному пересыпанью из пустого в порожнее” (ibid.), а это выражение в данном контексте указывает именно на гомогенность действительности и его толкования.

В этом же втором аспекте модели дискредитации полноты возникает и семантизация исчезновения начала и конца; сообщается о такой связной континуальности, где стирается сегментация времени, т. е. проведение границ между индивидуальными временными отрезками. Один промежуток времени таков же, как другой, ведь все элементы мышления, 
принадлежащие к разным этапам, оказываются лишь аналогичными вариантами того же содержания, циклически и беспрерывно повторяясь. Все это придает ощущению времени слитность и единообразие, вместо линеарной динамики преображения. По сути дела с этим связано и то, как вообще уничтожают себя дихотомические оппозиции (не только начало и конец), когда доводясь до максимума - до крайностей, до конца, с установкой на максимальную полноту - они начинают перевоплощаться друг в друга; между ними стирается граница, т. е. они становятся эквивалентами (бывает, что в каком-то крайнем пункте герой начинает испытывать именно противоположное чувство). Выясняется, что одно то же, что другое.

Третий аспект семантизации, исчерпывающее деление мира, с семиотической точки зрения обладает недостатком селекции самых важных индивидуализированных признаков комплексной действительности. Такое семиотическое “поведение" считает одинаково важными все компоненты, без иерархии, ведь ни одна отделенная от других деталь не получает приоритета.

Читатель сталкивается с семантической моделью одно то же, что другое гораздо разнообразнее, чем это осознает сам герой ЗИП. В более общем плане проблема вырисовывается как недостаток, нехватка в самом познавательном акте. Там элементы действительности получают однородную слитность. То же самое характеризует и сам процесс познания вместе с познающим субъектом. В тексте ему приписывается устойчивое свойство: он не способен понимать и формулировать индивидуальность и своеобразие с помощью отличительных признаков, которые должны трансформироваться во временной плоскости по законам процессуального развертывания. Перед глазами мир и субъект, которые страдают зафиксированностью идентификации, в основе которой лежит принцип одинаковой, однородной, единой, общей признаковости. Из этого источника возникает ощущение субъекта всегда переживать одно и то же в плане экзистенциального опыта, в области мышления и чувств, в слитном континууме времени без продвижения вперед. (“Это сорокалетнее мое убеждение. Мне теперь сорок лет, а ведь сорок лет - это вся жизнь”, 100; “тут сорок лет подполья!”, 115).

Отдельно следует говорить о том, что появляется и другой способ познания, который условно можно определить как смысловой конструкт илиили, когда можно выбрать из двух четко определенных элементов мира и системы его толкования. Но такой выбор, в конечном счете, не работает, не содействует комплексному познаванию многосоставной действительности. В итоге оказываются одинаковыми в своей безрезультативности как рассудочная логика, так и “проба увлекаться своим чувством слепо”, т. е. выбор четко маркированных, индивидуализированных путей, по принципу 
или-или, среди которых находится и выбор “без рассуждений, без первоначальной причины, отгоня[ть] сознание”, “возненавидеть или полюбить”. Все равно, что́ выбирается по принципу или-или, при любом выборе остается “умышленное пересыпанье из пустого в порожнее”. Логика обсуждения по выбору или-или появляется, например, и в той уже процитированной аргументативной части, где подпольный человек объясняет, почему он без вины виноват по законам природы: “Потому, во-первых, виноват, что [...]. Потому, наконец, виноват, что если 6 и [...]. Наконец, если б даже я [...]” (103) - хотя тут перечисление причин виноватости идет по линии градации, согласно имплицитной логике “во-первых”, “во-вторых”, “в-третьих”, совершенно ясно, что было бы достаточно выбрать хоть один компонент аргументации, чтобы выяснить собственное убеждение и констатировать факт.

Общее инвариантное смысловое образование в семантизации перспектив полноты соответствует модели, сформированной в “Герое нашего времени", где формация одно то же, что другое проходит через трансформа-

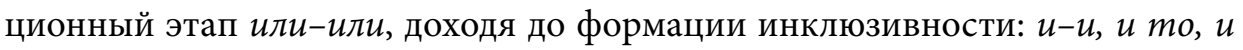
другое. Такой трансформационный ряд охватывает разные пласты текста, от событийного сюжета до авторефлексивности романа (Kroó 2015). В ЗИП формация или-или предполагает выбор из индивидуализированных элементов мира (как было указано, такими являются противопоставленные тезисы и антитезисы всякого рода или мысль $я$ vs oнu), но эти противоречия, достигая своих крайних пунктов, тоже уничтожаются, когда унифицируются конфликтные признаки; следовательно, опять наступает состояние беспризнаковости. ${ }^{11}$ Любопытным примером потери семантических характеристик может служить глубоко ироническая интонация, которую содержит тематизация возможного выбора “пить за здоровье всего прекрасного и высокого” или пить за здоровье “кого угодно” - эти возможности получают характеристику (конечно, в ироническом ключе) в следующем утверждении: “такие отзывы преприятно слышать в наш отрицательный век” (110). Ирония проявляется в том, что можно было бы считать красивым и высоким все в одинаковой мере (а ведь это новая форма беспризнаковой гомогенности действительности). К примерам могут относиться все неудачные попытки, говорящие о неадекватно концептуализированных

11 См.: “Скажите мне вот что: отчего так бывало, что, как нарочно, в те самые, да, в те же самые минуты, в которые я наиболее способен был сознавать все тонкости «всего прекрасного и высокого» [...] мне случалось уже не сознавать, а делать такие неприглядные деянья, такие, которые... [...] как нарочно, приходились у меня именно тогда, когда я наиболее сознавал, что их совсем бы не надо делать?” (102). 
выборах между “я” и “они” или “я” и “она” (Лиза). Посредством таких выборов подпольный человек стремится сотворить понятие и опыт “мы вместе” (т. е. образование $u$ mo, $и$ другое), но ложным путем, потому что везде исчезает индивидуализированность тех противоположных компонентов мира, которые должны совместиться в единстве (например, подпольный человек не понимает Лизу, как индивида, причисляет ее к классу, типу, и т. д., лишь позже осознавая, кто она в действительности).

\section{4. Маркированные противоречия - монодуалистическая антиномия}

Проблема превращения беспризнаковой характеристики в признаковую (индивидуализация знака в рамках маркированности) и включенности знаков в структуру совместимости противоречий в повести Достоевского поставлена с семиотической перспективы как вопрос специфического соотношения между означающим и означаемым. Речь идет о том, как познаваемый объект должен отделяться от других познаваемых объектов, и таким же образом и означающее его свойство (знаковая отмеченность) должно отличаться от других. В ЗИП Достоевского бросаются в глаза постоянные поиски форм обозначения подходящими знаками (означающими), которые способствуют адекватному семиотическому определению, нужному для полного познания. В таком духе подпольный человек ищет, например, среди выгод, такое выгодное, что противоречит продиктованной математической формуле выгоды, т. е. - цитируем - “всего выгоднее” (115). Это воплощается в следующем новом выражении: “самая выгодная выгода [...], которая главнее и выгоднее всех других выгод” (111). А такой поиск и есть то, что противореча рассудку может представить собой свободное человеческое хотение как черту самостоятельной личности и индивидуальности (см. подобный прием определения в случае лентяя, который “не простой, a, например, сочувствующий всему прекрасному и высокому”, в противоположность идее не уметь стать “ни зльм, ни добрым, ни подлецом, ни честньм, ни героем, ни насекомым" (100).

Индивидуализация описываемых объектов и сам процесс познания приводят к тому, что смысловое образование $u-u$ (в концептуализации “мы с Тобой” или “мы с вами” или в понимании “живой жизни” и т. д.), представляющее собой совмещение двух обособленных друг от друга компонентов мира и их качеств, тезисов и антитезисов, положительных и негативных оценок и описаний, утверждений и отрицаний в инклюзивном единстве, 
в контексте философской традиции следует интерпретировать как проявление монодуалистической антиномии. Такой монодуализм идет в противоположность логике тезиса-антитезиса-синтеза в том духе, как Ксана Бланк, следя за философской историей данного типа мышления, выделяет его принцип (Blank 2007). Определение монодуализма в указанной работе доводится до интеграции понимания бахтинского толкования открытости и состояния взаимного рефлектирования ${ }^{12}$ (см. особенно Blank 2007: 29-32; об апофатическом Бахтине см. Poole 2001).

В этом свете можно толковать характеристику подпольного человека, одержимого своей ориентированностью на полноту, а в то же время ясно осознающего собственные противоречия: “я поминутно сознавал в себе много-премного самых противоположных тому элементов. Я чувствовал, что они так и кишат во мне, эти противоположные элементы. Я знал, что они всю жизнь во мне кишели и из меня вон наружу просились, но я их не пускал” (100). В жизни нарочно не выпущенные “наружу” - хотя и постоянные - противоречия должны выпускаться в акте писания. Это воплощается в иной форме, чем та, которая на более раннем этапе жизни подпольного человека возникала как “истерическая жажда противоречий, контрастов”, поэтому он и “пускался развратничать” (127). В основном в подобном духе он говорит о “выгоднее всех выгод[е]” при предположении, что она “nротиворечит самым здравым заключениям [...] рассудка о выгодах” (115). Противоречия в этом контексте становятся признаками личности и индивидуальности. Двойственное семантическое определение подпольного человека совмещает установку на противоречивость (сохранение маркированных противоположных элементов) и достижение - в том числе и семантической - полноты. Именно такими качествами обладает фигура монодуалистической антиномии. Рабочее семантическое образование $u-u$, резко противопоставленное формации или-или, вырисовывает определенныцй образ семантической полноты, основанной на соположении маркированной признаковости обоих компонентов антиномии, которые сохраняются.

Противоречивость содержит в себе и апофатическое изложение, с толкования которого началось представление трех компонентов изучения контекста литературной традиции ЗИП. Апофатическое содержит в себе код многоаспектности противоречий. Он сводится к проявлениям совместимых оппозиций между существованием и несуществованием; между

12 Специальный разбор разновидностей рефлективности в ее “апофатическом измерении”, помимо прочего с точки зрения вопроса вынесения практических решений, см. Mouzelis 2010. 
разными - трансцендентной и когнитивной - онтологическими сферами; невербальным бытием и вербальным его познанием и выражением (ср. творческое свойство последнего); означающим (отрицание) и означаемым (утверждение). Все эти аспекты ставят вопросы о семиотическом существовании знаком и в знаке в познавательном процессе реципиента действительности и субъекта ее описания. Апофатическое интерпретирует полноту в рамках двухстороннего действия знака как означающего и означаемого и представляет собой par excellence взаимную рефлексивность, усиленное проецирование элементов оппозиции друг на друга.

Такая семантика и рамки действия познания в поэтике Достоевского подчеркнуто поставлены в контекст осмысления динамики процессуальности, что предполагает линеарное развертывание во времени. Апофатизм, таким образом, содержащий в себе интенсивный код семиотического действия, в поэтике Достоевского доминантно понимается в своем динамическом разыгрывании. Апофатизм представляет собой в данном контексте образование $u$ это - $u$ mо, толкуемость которого обеспечена лишь в том случае, если оба элемента расположены на временной оси, и если может рассматриваться контекст развития этой инклюзивной формации, т. е. уловимо его место в трансформационном сюжете, который начинается на семантическом этапе одно то же, что другое. Смысловой конструкт $u$ это - $и$ то имеет смысл, если все противопоставленные элементы индивидуализированы, только тогда они не оказываются “книжным” повтором 13 уже готовых формы и содержания. Таким образом, акцент ставится вместо имитативного повтора (одно то же, что другое : унификация признаков, беспризнаковость) на креативный трансформационный повтор семиотического характера. ${ }^{14}$ Трансформация проводит границу между временными сегментами. И в конечном итоге трансформация воплощает семиотический процесс, всегда открытый к очередным новым обновлениям, основанным на индивидуализации знаков, доведенных до максимума.

А само произведение Достоевского в целом, как текстовая полнота, развертывается как ряд разных типов дискурса от набора сентенций, включенных в часть Подполье, через По поводу мокрого снега, жанр, тематизированный как отодвижение от анекдота к повести подпольного человека,

13 Ср.: “Я знал, что говорю туго, выделанно, даже книжно, одним словом, я иначе и не умел, как «точно по книжке»" (Dostoevskij 1973a: 162). О мотиве книжность/книжное с семиотической перспективы в контексте Записок из подполья см. Kroó 2019.

14 О принципе креативного семиотического расширения, помимо прочего, в смысле открытости, в контексте энциклопедии, см. Eco 1984; cp. Kelemen 1987, 2004. Подробное толкование см. Kroó 2019. 
а затем включенный в его Записки как целостный текст, который наглядно отделяется разными дистанцирующими жестами от произведения Достоевского ЗИП. Это последнее интегрирует все текстовые формации по логике их перевоплощений. Они все вместе действенны в трансформационном ряду. И то, и другое, и третье нужны и для читателя, чтобы понять смысл модели творения, в которой воплощается уход от имитативных повторов, от миметической инертности готовых схем интеллектуальных конструкций (научных формул, книжной заданности, общественных норм поведения, непосредственного диктума законов человеческой природы и т. д. и т. п.) к принципу семиотической дифференциации, лежащей в основе семиотического творения и толкования мира и культуры.

\section{5. Некоторые выводы о концептуализации культурной традиции с семиотической перспективы}

Через предложенную выше модель творения, созданную поэтическим словом Достоевского, определяется природа традиции в смысле известного, готового, канонизированного культурного материала, который, однако, не может существовать и распознаваться без постоянного его обновления в процессе перевоплощений. Мы исходили из трех аспектов диахронической парадигматичности - (1) модель отрицания (апофатизм), (2) семантизация полноты и (3) установка на проблематизацию семиотичности мышления и дискурса. Эти три компонента, которые в разных главах настоящей статьи основательно рассматривались, оказались тесно взаимосвязанными. Через них в повести Достоевского, в разных формах смысловых проекций, развертывается модель творения, воплощающая идею, что литературная традиция является частью творческого культурного мышления - она не готовая, законченная заданность, а открытая процессуальность. В тексте ЗИП не только указываются разные корни литературной традиции, к которым художественный дискурс восходит. Они “встречаются” и функционируют в одном семантическом образовании, порождающем модель семиотического творения. Эта модель включает в себя толкование литературной традиции в контексте динамики культуры, заложенной в инновативном характере семиотического мышления и возникновения интерпретирующих дискурсов. Авторефлексивный слой текста Достоевского определяет ЗИП в качестве творческого агента перевоплощения культурной традиции, интегральной частью которой является не простое самоописание, а именно семиотическое самотолкование. Для такого толкования характерно 
то, что оно в итоге не отрицает (и, таким образом, не исключает) известные и противопоставляемые формы проявления и описания культурного мышления (разные интерпретации мира и дискурсов/текстов), а включает их во все более и более расширяющееся пространство культурной парадигматичности, сохраняя память о них в творческих актах семиотического перетворения. ${ }^{15}$

\section{Литература}

Blank, Ksana 2007. The Rabbit and The Duck: Antinomic unity in Dostoevskij, the Russian religious tradition, and Mikhail Bakhtin. Studies in East European Thought 59: 21-37. https://doi.org/10.1007/s11212-007-9019-6

Conte, Maria-Elisabeth; Petöfi, János S; Sözer, Emel (eds.) 1989. Text and Discourse Connectedness. Proceedings of the Conference on Connexity and Coherence, Urbino, July 16-21, 1984. (Studies in Language Companion Series 16.) Amsterdam: John Benjamins Publishing Company. https://doi.org/10.1075/slcs.16

Dostoevskij, Fyodor M. 1973a. Zapiski iz podpol'ya. In: Polnoe sobranie sochinenij $v$ tridtsati tomah. T. 5. Povesti i rasskazy. 1862-1866. Igrok. Leningrad: Nauka, Leningradskoe otdelenie, 99-179. [Достоевский, Ф. М. 1973a. Записки из подполья. Полное собрание сочинений в тридиати томах. Т. 5. Повести и рассказы. 1862-1866. Игрок. Ленинград: Наука, Ленинградское отделение, 99-179.]

Dostoevskij, Fyodor M. 1973b. Polnoe sobranie sochinenij v tridtsati tomah. T. 8. Idiot. Leningrad: Nauka, Leningradskoe otdelenie. [Достоевский, Ф. М. 1973b. Полное собрание сочинений в тридияати томах. T. 8. Идиот. Ленинград: Наука, Ленинградское отделение].

Dostoevskij, Fyodor M. 1974. Polnoe sobranie sochinenij v tridtsati tomah. T. 10. Besy. Leningrad: Nauka, Leningradskoe otdelenie. [Достоевский, Ф. М. 1974. Полное собрание сочинений в тридиати томах. Т. 10. Бесы. Ленинград: Наука, Ленинградское отделение].

Eco, Umberto 1984. Dictionary vs. encyclopedia. In: Semiotics and the Philosophy of Language. London: Macmillan, 46-86.

Emerson, Caryl 2001. Afterword: Plenitude as a form of hope. In: Felch, Susan M.; Contino, Paul J. (eds.), Bakhtin and Religion: A Feeling for Faith. Evanston: Northewestern University Press, 177-192.

15 Исследование выполнено при финансовой поддержке РФФИ в рамках научного проекта № 19-512-23008\19. В проекте с венгерской стороны участвует Университет имени Лоранда Этвеша - Будапешт (Eötvös Loránd University - Budapest). Исследование реализовано также в рамках Программы повышения конкурентоспособности Томского политехнического университета. 
Hansen-Löve, Aage A. 1996. Diskursivnye processy v romane Dostoevskogo "Podrostok". In: Markovich, Vladimir M.; Schmid, Wolf (eds.) Avtor i tekst. Sbornik statej. SanktPeterburg: Izdatel'stvo Sankt-Peterburgskogo universiteta, 229-267. [Хансен-Леве, Оге 1996. Дискурсивные процессы в романе Достоевского «Подросток». In: Маркович, В. М.; Шмид, Вольф (ред.), Автор и текст. Сборник статей. СанктПетербург: Издательство Санкт-Петербургского университета, 229-267.]

Kelemen, János 1984. Eco két szemiotikája. In: A nemes hölgy és a szolgálóleány. Budapest: Gondolat Kiadó, 153-168.

Kelemen, János 2007. A rózsa neve és Eco szemiotikája. In: Eco visszhang. Kelemen János tanulmányai Umberto Ecóról. (Világosság könyvek 3.) Budapest, 131-152.

Kroó, Katalin 2015. "Odno - to zhe, chto drugoe" kak transformatsionnyj semanticheskij konstrukt v romane Lermontova “Geroj nashego vremeni”. In: Dergachevskie chteniya 2014. Ekaterinburg: Izdatel'stvo Ural'skogo universiteta, 152-164. [Кроо, Каталин 2015. «Одно - то же, что другое» как трансформационный семантический конструкт в романе Лермонтова «Герой нашего времени». Дергачевские чтения - 2014. Екатеринбург: Издательство Уральского университета, 152-164.]

Kroó, Katalin 2019. What is "bookish"? A poetic metaphor in terms of the semiotic model of creation. In: Kroó, Katalin (ed.), The Book Phenomenon in Cultural Space/A könyvjelenség a kulturális térben. Budapest, Tartu: Eötvös Loránd University, International Semiotics MA and "Russian Literature and Literary Studies" Doctoral Programme; University of Tartu, Transmedia Research Group (National Professorship of Cultural Semiotics), 33-47.

Lahusen, Thomas 1987. Inversiya utopicheskogo diskursa: O Zapiskah iz podpol'ja F. M. Dostoevskogo. [Лахузен, Томас. Инверсия утопического дискурса. О Записках из подполья Ф. М. Достоевского.] Wiener Slawistischer Almanach 20: 5-40.

Lermontov, Mikhail Yu. 2000. Geroj nashego vremeni. In: Polnoe sobranie sochinenij v 10 tomah. T. 6. Proza. Moscow: Voskresen'e, 212-366. [Лермонтов, М. Ю. 2000. Герой нашего времени. Полное собрание сочинений в 10 томах. Т. б. Проза. Москва: Воскресенье, 212-366.]

Lotman, Juri M. 1988. Syuzhetnoe prostranstvo russkogo romana 19 stoletiya. In: V shkole poeticheskogo slova: Pushkin. Lermontov. Gogol'. Moscow: Prosveshchenie, 325-348. [Лотман, Ю. М. 1988. Сюжетное пространство русского романа ХІХ столетия. В школе поэтического слова: Пушкин. Лермонтов. Гоголь. Москва: Просвещение, 325-348.]

Lunde, Ingunn 2001. 'Ia gorazdo umnee napisannogo': On apophatic strategies and verbal experiments in Dostoevskij's "A Raw Youth". The Slavonic and East European Review 79(2): 264-289.

Martinsen, Deborah 2006. Of shame and human bondage: Dostoevsky's Notes from Underground. In: Young, Sarah; Milne, Lesley (eds.), Dostoevsky on the Threshold of Other Worlds: Essays in Honour of Malcolm V. Jones. Ilkeston: Bramcote Press, 157-169. Mouzelis, Nicos 2010. Self and self-other reflexivity: The apophetic dimension. European Journal of Social Theory 13(2): 271-284. https://doi.org/10.1177/1368431010362299

Poole, Randall A. 2001. The apophatic Bakhtin. In: Felch, Susan M.; Contino, Paul J. (eds.), Bakhtin and Religion. A Feeling for Faith. Evanston: Northewestern University Press, 151-175. 
Savinkov, Sergej V.; Faustov, Andrej A. 2014. Pechorin kak "strannyj” chelovek: "vampiricheskij" element v romane "Geroj nashego vremeni". In: Bogatyrev, Dmitri K. (otv. red.); Savinkov, S. V.; Isupov, Konstantin G. (sost.). M. Yu. Lermontov: Pro et contra. Lichnost' $i$ idejno-hudozhestvennoe nasledie M. Yu. Lermontova $v$ otsenkah otechestvennyh i zarubezhnyh issledovatelej i myslitelej. Antologija. T. 2. St. Petersburg: Izdatel'stvo Russkoj hristianskoj gumanitarnoj akademii, 572-583. [Савинков, C. В.; Фаустов, А. А. 2014. Печорин как «странный» человек: «вампирический элемент» в романе «Герой нашего времени». Богатырев, Д. К. (отв. ред.); Савинков, С. В.; Исупов, К. Г. (сост.) М. Ю. Лермонтов: pro et contra. Личность и идейно-художественное наследие М. Ю. Лермонтова в оиенках отечественных и зарубежных исследователей и мыслителей. Антология. Т. 2. Санкт-Петербург: Издательство Русской христианской гуманитарной академии, 572-583.]

Schmid, Wolf 1973. Proza Pushkina v poeticheskom prochtenii: "Povesti Belkina" $i$ "Pikovaja dama”. (Per. s nem. A. I. Zherebina (I i II chasti); 2-e izd., isprav. i dop.) St. Petersburg: Izdatel'stvo Sankt-Peterburgskogo universiteta. [Шмид, Вольф 1973. Проза Пушкина в поэтическом прочтении: «Повести Белкина» и «Пиковая дама»; пер. с нем. А. И. Жеребина (I и II части); 2-е изд., исправ. и доп. СПб.: Издательство СанктПетербургского университета.]

Turgenev, Ivan S. 1980. Dnevnik lishnego cheloveka. In: Polnoe sobranie sochinenij $i$ pisem $v$ tridtsati tomax. Sochineniya. T. 4. Povesti i rasskazy. Stat'i i retsenzii. 18441854. Moscow: Nauka, 166-216. [Тургенев И. С. 1980. Дневник лишнего человека. Полное собрание сочинений и писем в тридиати томах. Сочинения. T. 4. Повести и рассказы. Статьи и рецензии. 1844-1854, Москва: Наука, 166-216.]

Zhirmunskij, Viktor M. 1960. Problemy sravnitel'no-istoricheskogo izucheniya literatur. Izvestiya AN SSSR. Otdelenie literatury i yazyka. T. 19. vyp. 3. Moscow, 177-186. [Жирмунский, В. М. 1960. Проблемы сравнительно-исторического изучения литератур. Известия АН СССР. Отделение литературы и языка. Т. ХІХ. Вып. 3. Москва 177-186.]

Zhivolupova, Natalya V. 2018. Problema avtorskoj pozitsii v “Zapiskah iz podpolya”. In: Problema avtorskoj pozitsii $v$ ispovedal'nom povestvovanii Dostoevskogo 60-70- $h$ gg. ("Zapiski iz podpol'ya”, "Podrostok"). Nizhnij Novgorod: D’yatlovy gory, 48-132. [Живолупова Н. В. 2018. Проблема авторской позиции в «Записках из подполья» Достоевского. Проблема авторской позиции в исповедальном повествовании Достоевского 60-70-х гг. («Записки из подполья», «Подросток»). Нижний Новгород: Дьятловы горы, 48-132.]

\section{Dostoevsky's Notes from the Underground in the light of literary tradition: A semiotic approach}

In the paper, Dostoevsky's novella Notes from the Underground is interpreted through the conceptualization of literary tradition within a semiotic framework, from three interconnected angles: the interpretation of (1) the discursive forms of negation (apophatism); (2) the semantization of the idea of 'plenitude' (fullness, totality, completeness); (3) the text's concentrated reflection on the semiotic nature of the modelled world and its (meta) 
poetic language. Apophatic poetics calls attention to the conflictual relationship between the signifier and the signified, including the paradoxical situation in which intensive sign articulation/expression is given to some substance considered to be unexpressable. Signification here strives to gain epistemological knowledge about the potentials of the existence of personality through its definition in terms of non-existence or ambivalent, unproductive existence. The character definition, putting in centre stage - within the problematics of personhood and personality - the protagonist's desire to achieve the state of plenitude, also gains a semiotic orientation through the conflict between being endowed with vs. being deprived of individual semantic attributes accorded to the object of cognition (individualization vs. generalization). The paper examines the semantic modelling of 'plenitude' and explains the various means that this model is discredited by the object's lack of individual semantic attributes in (a) causality; (b) temporal segmentation; (c) the forms of exhaustive detailing. Individual object identification is also interpreted as preserving oppositions at the levels of literary character (his contradictions) and abstract notions (theses and antitheses) in which conflicting elements constitute an organic whole. This can be traced back to monodualistic antinomies deeply rooted in the Russian philosophy of religion.

\section{F. Dostojevski “Ülestähendusi põranda alt" kirjandustraditsiooni kontekstis: semiootiline lähenemine}

Artiklis analüüsitakse Dostojevski jutustust kirjandustraditsiooni kontseptualiseerimise semiootilises raamistikus kolmest erinevast vaatepunktist: (1) eituse diskursiivsed vormid (apofatism); (2) täielikkuse idee semantiseerimine ja (3) kunstiteksti orienteeritus selles kujutatava maailma semiootilise olemuse ja seda kirjeldava (meta)poeetilise keele mõtestamisele. Kui apofaatiline poeetika problematiseerib võimalust artikuleerida väljendamatut keelelise dünaamika intensiivsetes vormides ja teadvustada isiksuse olemise perspektiive mitteolemise või ambivalentse/ebaproduktiivse olemise vormide kirjelduses, siis Dostojevski jutustuses leiab tunnetusobjekti määratlemisel aset mittetunnuslikkuse oluline tähendustamine. Artiklis jälgitakse 'täielikkuse' semantilise modelleerimise ja selle diskrediteerimise protsessi kolmes suunas: (a) põhjus-tagajärg motivatsioon; (b) ajaline segmenteeritus; (c) detailsus objekti kirjelduses. Semiootiline dünaamika "Ülestähendustes põranda alt" on seotud markeeritud vastuolude (nii karakterioloogias kui ideede tasandil - teesid ja antiteesid) ja nende ühendamisega semiootilises inklusiivsuses. See omakorda viib monodualistliku antinoomiani, mis on vene kultuuri filosoofilis-religioosses traditsioonis sügavalt juurdunud. Dostojevski teose tekstilist dünaamikat tõlgendatakse transformatsioonimudeli raamistikus: üks on sama mis teine (tunnetusobjektide unifitseerimine) $\rightarrow$ kas-või (tunnetusobjektide markeeritud individualiseeritud atribuutide valikul nende vastastikune välistamine) $\rightarrow$ nii see $k u i$ ka teine (vastanduste ühendamine, vastandite ühtsus). Taolises transformatsioonimudelis on olemuslikult kohal ka semiootilise kreatiivsuse tõlgendus, mille valguses Dostojevski määratleb kultuuritraditsiooni ja mille dünaamikat iseloomustab protsessuaalsus ja avatus. 